\title{
Seroprevalence of human Brucellosis and associated risk factors among high-risk occupations in Mbeya Region of Tanzania
}

Frederick D. Sagamiko ${ }^{1,2}$, Ruth L. Mfune ${ }^{* 1,3}$, Bernard M. Hang'ombe ${ }^{1}$, Esron D. Karimuribo ${ }^{4}$, Alfred M. Mwanza ${ }^{1}$, Calvin Sindato ${ }^{5}$, John B. Muma ${ }^{1}$

${ }^{1}$ School of Veterinary Medicine, University of Zambia, Lusaka, Zambia

${ }^{2}$ Maswa District Council, Simiyu, Tanzania

${ }^{3}$ Michael Chilufya Sata School of Medicine, Copperbelt University, Ndola, Zambia

${ }^{4}$ College of Veterinary and Biomedical Sciences, Sokoine University of Agriculture, Morogoro, Tanzania

${ }^{5}$ National Institute for Medical Research, Tabora, Tanzania

Received: February 24, 2020

DOI: $10.5430 /$ jer.v6n1p1
Accepted: May 18, 2020

URL: https://doi.org/10.5430/jer.v6n1p1
Online Published: June 3, 2020

\begin{abstract}
Background: Brucellosis is a bacterial zoonotic disease of public health and economic importance. A cross-sectional study was conducted in Mbeya region between November 2015 and January 2016 to investigate the seroprevalence of human brucellosis and identify associated risk factors among individuals in risky occupations.

Methods: A total of 425 humans from six occupational categories were serially tested for Brucella antibodies using the Rose Bengal Plate Test (RBPT) and competitive Enzyme Linked Immunosorbent Assay (c-ELISA), for screening and confirmation, respectively. A questionnaire survey was also administered to participants to collect epidemiological data.

Results: The overall seroprevalence among the occupationally exposed individuals was $1.41 \%$ (95\% CI: 00.64-3.12). Seroprevalence was higher among butcher men 5.6\% (95\% CI: 1.68-5.26), herds men 1.35\% (95\% CI: 0.18-9.02); and abattoir workers $1.1 \%(95 \%$ CI: $0.26-4.22)$ although there was no statistical significance. $(P$ value $=.18)$. Seroprevalence was also higher among men $(1.8 \%)$ compared to females $(0 \%)(P$ value $=.19)$. and also, among those aged $<11$ years $(2.5 \%)$. Individuals who consumed raw milk had a higher seroprevalence $(1.56 \%)$ compared to those who drunk boiled milk while seropositivity was $0.88 \%$ among those who assisted animals during parturition $(P$ value $=.49)$. Butcher men were at higher risk of exposure compared to other occupational categories. Our findings show the presence of brucellosis in occupationally exposed individuals in Mbeya region. Conclusion: There is need to sensitize the concerned professions in order to reduce the risk of acquiring Brucella infections from animals and animal products This also calls for public health awareness about the disease, and implementation of measures to prevent further spread of brucellosis within and outside the study area.
\end{abstract}

Key Words: Brucellosis, Human, Occupation, Seroprevalence, Risk factors

\section{INTRODUCTION}

Brucellosis is a bacterial zoonotic disease of public health and economic importance that affects domestic animals, wildlife and humans worldwide. ${ }^{[1]}$ There are currently twelve known host Brucella species, however, this number may change as new species continue to be discovered. ${ }^{[2]}$ Zoonotic

\footnotetext{
* Correspondence: Ruth L. Mfune; Email: lindizyani@gmail.com; Address: School of Veterinary Medicine, University of Zambia, P.O. Box 32379, Lusaka, Zambia. 
infections are mainly attributed to B. melitensis, B. abortus, and B. suis, ${ }^{[3]}$ while B. canis has been mainly reported as an occupational hazard among veterinarians and laboratory workers. ${ }^{[4]}$ Human brucellosis is a highly debilitating infection that presents as an acute febrile flu-like illness. ${ }^{[5]}$ It is characterized by symptoms such as fever, anorexia, fatigue, headaches, depression and weight loss that may easily be confused with malaria or typhoid. ${ }^{[6]}$ The source of human infection always resides in domestic or wild reservoirs. It has been observed that most cases of human brucellosis occur in rural areas where people live in close proximity with their livestock and consume raw milk and milk products. ${ }^{\left[{ }^{[, 8]}\right.}$ However, information on the brucellosis situation in Sub-Saharan Africa is scarce, particularly in humans. Some studies have reported human brucellosis at seroprevalences ranging from $0.02 \%$ to $33.3 \%$ in Zambia, Nigeria, Ghana, Cameroon, Sudan and Ethiopia. ${ }^{\left[{ }^{9-15]}\right.}$ In Tanzania, several studies have been done in Katavi, Manyara, Morogoro, Northern Tanzania, Mwanza and Tanga regions which have reported human brucellosis at seroprevalences ranging from 0.6 to $48.4 \% .^{[16-23]}$ However, there is no previous report on the disease among the high-risk human population in Mbeya region. Therefore, this study was aimed at establishing the seroprevalence and associated risk factors of human brucellosis among occupationally exposed individuals in Mbeya region, Tanzania.

\section{MATERIALS AND METHODS}

\subsection{Study area}

The study was carried out in Mbeya Region in the Southern highlands of Tanzania between November 2015 and January 2016 in three selected districts namely; Mbarari, Mbeya and Momba. Geographically, Mbeya region lies about 5,500 feet above sea level and experiences subtropical highland climate with humid summers and dry winters. The temperature ranges between $-6^{\circ} \mathrm{C}$ in the highlands and $29^{\circ} \mathrm{C}$ on the lowlands, while the average rainfall is $900 \mathrm{~mm}$ per year. Details of the study area have been described in our earlier publication. ${ }^{[24]}$ According to the 2012 national census, the region has an estimated human population of about 2,707, among which 1, 297,738 are males and 1, 409, 672 are females. A majority of the population $(1,809,298)$ dwell in the rural areas whereas 898,112 are found in urban areas. ${ }^{[25]}$

\subsection{Study population}

The study population consisted of two groups. One group consisted of individuals from households where cattle had tested positive for Brucella from our earlier cattle survey. ${ }^{[24]}$ The second group consisted of purposively sampled high -risk individuals that were involved in the cattle value chain: livestock officers, herdsmen, butcher men and abattoir workers.

\subsection{Study design and sample size calculation}

This was a cross-sectional study that was strategically designed in order to determine the seroprevalence of human brucellosis in high-risk individuals. The sample size was pre-determined from our earlier study. A total of 425 humans were purposively sampled in this study which included herdsmen and milkers from the herds earlier screened against brucellosis. ${ }^{[24]}$ These included 74 herdsmen and 72 milkers, 184 abattoir workers from all 3 butcheries in the 3 districts, 54 butcher men, 11 livestock officers and 30 other individuals.

The selected study region encompassed a strategic population of individuals whose culture encourages the use of animal products for proteins, thus predisposing them to zoonotic diseases.

\subsection{Collection of samples and epidemiological data}

A health personnel (phlebotomist) was assigned to aseptically collect $5 \mathrm{ml}$ of blood from the participant's brachial vein using a sterile disposable syringe into pre labelled plain vacutainer tubes. The samples were incubated overnight at room temperature and then centrifuged at $3000 \mathrm{xg}$ to get clear serum. All collected samples were assigned identification numbers and stored in a mobile refrigerator until shipment to the University of Zambia, Public Health laboratory where they were stored at -20 degree until serological analysis. A pre-tested structured questionnaire was administered to the participants in order to collect information on demographic data, socioeconomic data, variables on exposure to animals and animal products, consumption of dairy and animal source products.

\subsection{Laboratory analysis}

\subsubsection{Rose bengal plate test}

All collected sera samples were screened using Rose Bengal Plate Test (RBPT), antigen manufactured by Ubio Biotechnology Systems Pvt Ltd for detection of Brucella antibodies according to the test procedure recommended by OIE (1). Briefly, $20 \mu \mathrm{l}$ of RBPT antigen and $20 \mu \mathrm{l}$ of the test serum were placed alongside on one well of the glass plate and mixed thoroughly. The slide was gently rocked for 4 minutes and thereafter, any visible agglutination was considered as a presumptive positive result.

\subsubsection{Competitive enzyme-Linked immunosorbent assay (c-ELISA)}

RBPT positive sera were thereafter subjected to competitive Enzyme-Linked Immunosorbent Assay (c-ELISA) as a confirmatory test, adopting a test procedure and interpretation of results as recommended by the manufacturer (Svanova Biotech AB SE-751 Uppsala, Sweden) and as described by

ISSN 2377-9306 E-ISSN 2377-9330 
Muma et al. ${ }^{[26]}$ According to the ELISA kit manufacturer's instructions, serum was regarded as positive if the PI value was $>30 \%$. Only individuals that tested positive to both RBPT and c-ELISA were regarded as Brucella seropositive.

\subsection{Data management and analysis}

Data obtained from the serological tests and a questionnaire

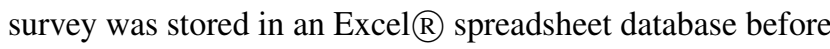
being imported into STATA $13 \AA$ statistical software for analysis. Categorical variables were summarized as frequency and percentages; continuous variables were summarized as mean or standard deviation (SD). $P$-values of .05 or less were considered statistically significant. A person was considered to be seropositive when tested positive to both RBPT and c-ELISA. The degree of association between each risk factor was assessed using the chi-square test and for all analysis, a $p$-value of $\leq .05$ was taken as significant.

\subsection{Ethical consideration}

Ethical approval (reference number NIMR/HQ/R.8a/Vol.1X/ 2050) was obtained from the Medical Research Committee of the United Republic of Tanzania prior to the study. Individual written consent was obtained from guardians for individuals that were less than 18 years prior to enrollment. Informed consent was obtained from all participants using written and verbal explanation of the study purpose and procedure in the Swahili language.

\section{RESUlts}

The overall seroprevalence for human brucellosis in Mbeya was $1.41 \%$ (95\% CI: 0.64-3.12) (see Table 1). Mbeya district had the highest seroprevalence $(1.88 \%)$ while Momba district did not record any seropositive individuals (see Table 1).There was no statistically significant association between district and seropositivity $(P$ value $=.85)$.

None of the female participants were seropositive $(0 \%)$ compared to men $(1.8 \%)$. The highest seroprevalence was recorded among butcher men (5.6\%) followed by herdsmen $(1.35 \%)$ and abattoir worker (1.1\%) as shown (see Table 2). Furthermore, seroprevalence was higher among individuals that were aged less than 11 years $(2.5 \%)$ compared to those aged between 11 and 20 years (1.02\%). Results showed that $75.3 \%$ of respondents consumed raw milk while $27 \%$ assisted their animals during parturition (see Table 2). A higher seroprevalence (1.56\%) was recorded among individuals who consumed unboiled milk compared to those who assisted in parturition $(0.88 \%)$ (see Table 2). Results from univariate analysis show that there was no statistical association between the hypothesized risk factors and Brucella seropositivity (see Table 2).
Table 1. Overall Seroprevalence of human brucellosis by district in Mbeya region

\begin{tabular}{lllll}
\hline District & No & Seropositive (\%) & 95\% CI & P value \\
\hline Mbarari & 220 & 1.36 & $0.44-4.12$ & \\
Momba & 45 & 0.00 & 0.00 & .85 \\
Mbeya & 160 & 1.88 & $0.06-5.68$ & \\
Overall & 425 & 1.41 & $0.64-3.12$ & \\
\hline
\end{tabular}

\section{Discussion}

\subsection{Seroprevalence of human brucellosis}

The aim of this study was to estimate the seroprevalence of human brucellosis and identify associated risk factors among high-risk occupations in Mbeya region of Tanzania. The overall seroprevalence found among butcher men, abattoir workers and herdsmen $(1.41 \%)$ is different from the rates reported in other parts of Tanzania namely; $5.52 \%$ among high-risk groups in Tanga region, ${ }^{[23]} 1.5 \%$ and $14.1 \%$ among agro-pastoral herders in Katavi and Mwanza regions respectively ${ }^{[19,20]}$ and $48.4 \%$ among abattoir workers and meat vendors in Mwanza region. ${ }^{[21]}$ The difference can be due to variations in study population, geographical locations and the use of Serum Agglutination Test (SAT) and Microscopic Agglutination Test (MAT) in the previous studies which had specificity and sensitivity of $95.7 \%$ and $55.3 \%$ respectively. Similar studies in Cameroon, Ethiopia and Nigeria among abattoir workers found seroprevalences of $5.6 \%, 4.7 \%$ and $33.4 \%$ respectively, ${ }^{[10,12,18]}$ while another one in Ghana among cattle handlers and slaughterhouses workers found seroprevalences of $10.1 \%$ and $1.8 \%$ respectively. ${ }^{[1,15]}$ In contrast, similar studies in South Sudan and Uganda found seroprevalences of $33.3 \%$ and $4.4 \%$ among cattle herders and livestock farmers respectively. ${ }^{[14,27]}$ These findings were higher than those from our study in all occupational groups except for the study among slaughterhouse workers in Ghana. ${ }^{[15]}$ Brucellosis has also been reported in butcher and slaughterhouse workers in Iran at 7.9\% seroprevalence. ${ }^{[28]}$ Our results show that brucellosis is present in high-risk populations in Mbeya region, even though the rate is lower than that reported in other population groups in other regions of Tanzania. The differences could possibly be due to small sample sizes, the different study populations and different diagnostic tests used in the other studies.

\subsection{Risk factors associated with Brucella seropositivity}

The prevalence of human brucellosis in occupationally exposed individuals in the Mbeya region of Tanzania varied with the occupational category, age, sex and milk consumption behaviour. However, there was no statistically significant association between the hypothesized risk factors and Brucella seropositivity. Butcher men had a higher risk of 
exposure to brucellosis than shepherds and abattoir workers, which agrees with findings from Tanga region. ${ }^{[23]}$ This could be attributed to that fact butcher men have a higher and constant exposure to slaughtered animal parts i.e. blood, tissues, fluids, with inadequate or poor use of protective wear. The risk of injury (knife-cuts) is also very high during this period as compared to the other categories, which increases the risk of exposure to the Brucella pathogen). Brucella seropositivity was higher in males $(1.41 \%)$ than females $(0 \%)$, similar to other findings ${ }^{[10,15,21,23,27]}$ but contrary to another. ${ }^{[18]}$ The high seroprevalence in males can be explained by the fact that most activities in the cattle value chain are carried out by males compared to females. The high disease prevalence among butcher men could be because they tend to spend longer periods handling animal carcasses usually without protective wear and are more likely to be injured when cutting meat and get infected. Hence, they are at a relatively higher risk of infection compared to other groups. Seroprevalence was higher in individuals aged 11 years and below $(2.5 \%)$. This is in contrast to ${ }^{[21]}$ but in agreement with $^{[15,29]}$ in Uganda and Ethiopia. This shows the traditional role that young male individuals play in livestock management where young men start herding livestock at a very young age. They spend more time in close contact with animals during their daily livestock activities, engage in consumption of unpasteurized milk directly from the teats of cows and assist during deliveries. This increases their risk of exposure to brucellosis. In our study, $75.3 \%$ of people consumed raw milk which was higher than the $12.8 \%$ reported by ${ }^{[29]}$ in Uganda. This can be explained by the fact that over $70 \%$ of milk sales in Tanzania is produced by pastoral farmers who do not believe or know that milk could be a potential source of infection to humans; and are not ready to subject their milk to heat treatment. ${ }^{[30]}$ Interestingly, seroprevalence was higher among individuals who did not assist their animals during parturition $(1.88 \%)$ than those who did $(0.88 \%)(P=$ 1.00). This could probably indicate that milk is a significant vehicle for transmission of Brucella infection and individuals with a history of consumption of raw milk were more likely to be infected. ${ }^{[29]}$ These study findings indicate that butchers and slaughterhouse workers in different areas face different risk levels towards zoonotic infectious diseases attributed to variation in infection rates among animals, differences in human lifestyle and use of PPE. It is possible that hygienic practices, regular medical check-ups and measures put in place by the local authorities can strongly influence the risk of brucella infections.

Table 2. Univariate analysis of seroprevalence of human brucellosis by different variables

\begin{tabular}{|c|c|c|c|c|c|}
\hline Variable & Category & $\begin{array}{l}\text { Total } \\
n=425\end{array}$ & $\begin{array}{c}\text { Seropositivity } \\
(\%)\end{array}$ & $\begin{array}{c}\text { Odds ratio } \\
(95 \% \mathrm{CI})\end{array}$ & $P$ value \\
\hline \multirow[t]{2}{*}{ Gender } & Male & 334 & 1.8 & $0.81-3.95$ & \multirow[b]{2}{*}{.198} \\
\hline & Female & 91 & 0 & & \\
\hline \multirow[t]{5}{*}{ Occupation } & Herdsmen & 74 & 1.35 & $0.18-9.02$ & \multirow{5}{*}{.180} \\
\hline & Livestock officers & 11 & 0 & 0.00 & \\
\hline & Butcher men & 54 & 5.6 & $1.68-5.26$ & \\
\hline & Abattoir workers & 184 & 1.1 & $0.26-4.22$ & \\
\hline & Milker & 72 & 0 & 0.00 & \\
\hline \multirow[t]{4}{*}{ Age } & $<11 \mathrm{yrs}$ & 155 & 2.5 & $0.94-6.54$ & \multirow{4}{*}{.396} \\
\hline & $11-20 \mathrm{yrs}$ & 196 & 1.02 & $0.25-4.01$ & \\
\hline & $21-30 \mathrm{yrs}$ & 70 & 0 & - & \\
\hline & $30 \mathrm{yrs}$ & 0 & 0 & - & \\
\hline \multirow[t]{2}{*}{$\begin{array}{l}\text { Consumption of } \\
\text { unboiled milk }\end{array}$} & Yes & 320 & 1.56 & $0.65-3.71$ & \multirow[t]{2}{*}{.54} \\
\hline & No & 105 & 0.95 & $0.13-6.54$ & \\
\hline \multirow[t]{2}{*}{ Assist in parturition } & Yes & 113 & 0.88 & $0.12-6.09$ & \multirow[t]{2}{*}{1.0} \\
\hline & No & 312 & 1.6 & $0.66-3.81$ & \\
\hline
\end{tabular}

\section{CONCLUSION}

This was the first serological study of human brucellosis in occupationally exposed individuals, specifically abattoir workers, butcher men and shepherds in Mbeya region. Seroprevalence was higher among butcher men, individuals below 11 years and among those who consumed raw milk. Occupa- 
tionally exposed individuals and the public need to be sensitized on brucellosis and the zoonotic dangers of consuming raw milk. There is also need for public health measures to prevent spread of the disease within and outside the study area.

\section{STUDY LIMITATIONS}

One of the limitations in this study was that some herds men from certain cattle herds whose animals were screened earlier could not participate in the study due to the migratory nature of agro-pastoralists in search of water and pasture.

\section{ACKNOWLEDGeMENTS}

This work was supported by the INTRA-ACP Mobility Support Project (Grant Agreement) 2012-3166). The authors would like to acknowledge Mr. Joseph Ndebe and Ms Jessica Chitambo for their assistance in the laboratory work, and the Health Department of Mbarara, Momba and Mbeya District Councils for their help during the sampling.

\section{CONFlicts OF INTEREST Disclosure}

The authors declare that they have no competing interests.

\section{REFERENCES}

[1] OIE. The Manual of Diagnostic Tests and Vaccines for Terrestrial Animals. 7th editio. 2012; 2: 819-1404. Available at: https: //www.oie.int/doc/ged/D12009.PDF

[2] Scholz HC, Revilla-Fernández S, Dahouk SAl, et al. Brucella vulpis sp. Nov., isolated from mandibular lymph nodes of red foxes (vulpes vulpes). Int J Syst Evol Microbiol. 2016 May 1; 66(5): 2090-8. PMid:26928956. https://doi.org/10.1099/ijsem.0.000998

[3] Seleem MN, Boyle SM, Sriranganathan N. Brucellosis: A reemerging zoonosis. Vet Microbiol. 2010 Jan; 140(3-4): 392-8. PMid:19604656. https://doi.org/10.1016/j.vetmic. 2009. 06.021

[4] Lucero NE, Corazza R, Almuzara MN, et al. Human Brucella canis outbreak linked to infection in dogs. Epidemiol Infect. $2010 \mathrm{Feb}$; 138(2): 280-5. PMid:19653929. https ://doi.org/10.1017/S0 950268809990525

[5] Ducrotoy M, Bertu WJ, Matope G, et al. Brucellosis in Sub-Saharan Africa: Current challenges for management, diagnosis and control. Acta Trop. 2017 (November); 165: 179-93. PMid:26551794. https://doi.org/10.1016/j.actatropica.2015.10.023

[6] Dean AS, Crump L, Greter H, et al. Clinical manifestations of human brucellosis: a systematic review and meta-analysis. PLoS Negl Trop Dis. 2012; 6(12): e1929. PMid:23236528. https ://doi .org/10 .1371 /journal.pntd.0001929

[7] Yumuk Z, O'Callaghan D. Brucellosis in Turkey - an overview. Vol. 16, International Journal of Infectious Diseases. 2012. PMid:22333223. https ://doi.org/10.1016/j.ijid.2011.12 .011

[8] Godfroid J. Brucellosis in livestock and wildlife: Zoonotic diseases without pandemic potential in need of innovative one health approaches. Arch Public Heal. 2017; 75(1): 1-6. PMid:28904791. https://doi.org/10.1186/s13690-017-0207-7

[9] Muma J, Samui I, Munyeme M, et al. Brucellosis in Rural Communities in Zambia and Factors Associated with Increased anti Brucellosis spp . antibody Presence Brucellosis in Rural Communities in Zambia and Factors Associated. UNZA J Sci Technol. 2008; 12(June): 9-18.

[10] Awah-Ndukum J, Mouiche MM, Kouonmo-Ngnoyum L, et al. Seroprevalence and risk factors of brucellosis among slaughtered indigenous cattle, abattoir personnel and pregnant women in Ngaoundéré, Cameroon. BMC infectious diseases. 2018 Dec 1; 18(1): 611. PMid:30509193. https ://doi .org/10.1186/s12879-018 $-3522-x$

Published by Sciedu Press
[11] Amegashie EA, Owusu-Dabo E, Salifu SP, et al. Sero-prevalence and occupational risk factors for Brucella infection among slaughterhouse workers and butchers in Kumasi, Ghana. J Epidemiol Res. 2016 Sep 18; 3(1). https ://doi.org/10.5430/jer.v3n1p17

[12] Tsegay A, Tuli G, Kassa T, et al. Seroprevalence and risk factors of brucellosis in abattoir workers at Debre Zeit and Modjo export abattoir, Central Ethiopia. BMC Infect Dis. 2017 Dec 26; 17(1): 101. PMid:28125966. https ://doi.org/10.1186/s12879-017 $-2208-0$

[13] Igawe PB, Okolocha E, Kia GS, et al. Seroprevalence of brucellosis and associated risk factors among abattoir workers in Bauchi State, Nigeria. Pan African Medical Journal. 2020 Feb 7; 35(33). https://doi.org/10.11604/pamj .2020.35.33.18134

[14] Nguna J, Dione M, Apamaku M, et al. Seroprevalence of brucellosis and risk factors associated with its seropositivity in cattle, goats and humans in Iganga District, Uganda. The Pan African Medical Journal. 2019; 33. PMid:31489077. https ://doi .org/10.11604/pamj . 2019.33 .99 .16960

[15] Tasiame W, Emikpe BO, Folitse RD, et al. The prevalence of brucellosis in cattle and their handlers in North Tongu District of Volta Region, Ghana. African journal of infectious diseases. 2016; 10(2): 111-7. PMid:28480445. https://doi.org/10.21010/ajid.v1 0 i2. 6

[16] John K, Fitzpatrick J, French N, et al. Quantifying risk factors for human brucellosis in Rural Northern Tanzania. PLoS One. 2010; 5(4). PMid:20376363. https://doi.org/10.1371/journal.pone.0 009968

[17] Bouley AJ, Biggs HM, Stoddard RA, et al. Brucellosis among hospitalized febrile patients in northern Tanzania. Am J Trop Med Hyg. 2012 Dec; 87(6): 1105-11. PMid:23091197. https://doi.org/ 10.4269/ajtmh.2012.12-0327

[18] James LW. Studies on human brucellosis in the Mikumi selous ecosystem, Morogoro, Tanzania (MSc Thesis, Sokoine University of Agriculture). Sokoine University of Agriculture. 2013.

[19] Assenga JA, Matemba LE, Muller SK, et al. Epidemiology of Brucella infection in the human, livestock and wildlife interface in the. BMC Vet Res. 2015; 1-11. PMid:26253151. https ://doi .org/10 .1186/s12917-015-0504-8

[20] Mngumi EB, Mirambo MM, Wilson S, et al. Predictors of specific anti-Brucella antibodies among humans in agro-pastoral communities in Sengerema district, Mwanza, Tanzania: the need for public awareness. Trop Med Health. 2016 Dec 18; 44(1):34. PMid:27857610. https://doi.org/10.1186/s41182-016-0034-5 
[21] Mirambo MM, Mgode GF, Malima ZO, et al. Seropositivity of Brucella spp. and Leptospira spp. antibodies among abattoir workers and meat vendors in the city of Mwanza, Tanzania: A call for one health approach control strategies. Foley J, editor. PLoS Negl Trop Dis. 2018 Jun 25; 12(6): e0006600. PMid:29939991. https://doi.org/10.1371/journal.pntd.0006600

[22] Carugati M, Biggs HM, Maze MJ, et al. Incidence of human brucellosis in the Kilimanjaro Region of Tanzania in the periods 2007-2008 and 2012-2014. Trans R Soc Trop Med Hyg. 2018 Mar 1; 112(3): 136-43. PMid:29697848. https ://doi .org/10.1093/trstmh/t ry033

[23] Swai ES, Schoonman L. Human Brucellosis: Seroprevalence and Risk Factors Related to High Risk Occupational Groups in Tanga Municipality, Tanzania. Zoonoses Public Health. 2009 May; 56(4): 183-7. PMid:18811674. https://doi.org/10.1111/j.1863-2 378.2008.01175.x3

[24] Sagamiko FD, Muma JB, Karimuribo ED, et al. Sero-prevalence of Bovine Brucellosis and associated risk factors in Mbeya region, Southern highlands of Tanzania. 2017. Available at: https://ac.els-cdn.com/S0001706X17309312/1-s2.0-S 0001706X17309312-main.pdf?_tid=6e2ff56d-b404-4b3 9-a53c-413f9394b45a\&acdnat $=1526644668 \_3 f f c 2 c a c 637$ 3cb01b05de5264d5f258e

[25] NBS. Tanzania National Bureau of Statistics - Tanzania in Figures 2012. Available at: https://www.nbs.go.tz/index.php/en/t anzania-in-figures/274-tanzania-in-figures-2012

[26] Muma JB, Lund A, Nielsen K, et al. Effectiveness of Rose Bengal test and fluorescence polarization assay in the diagnosis of Brucella spp. infections in free range cattle reared in endemic areas in Zambia. Trop Anim Health Prod. 2009 Jun; 41(5): 723-9. PMid: 18956247. https ://doi.org/10.1007/s11250-008-9244-0

[27] Madut NA, Muwonge A, Nasinyama GW, et al. The sero-prevalence of brucellosis in cattle and their herders in Bahr el Ghazal region, South Sudan. PLOS Neglected Tropical Diseases. 2018; 12(6): e0006456. PMid:29924843. https ://doi .org/10.1371/journa 1.pntd.0006456

[28] Esmaeili S, Naddaf SR, Pourhossein B, et al. Seroprevalence of brucellosis, leptospirosis, and Q fever among butchers and slaughterhouse workers in south-eastern Iran. PloS one. 2016; 11(1). PMid:26731333. https://doi.org/10.1371/journal. pone.0 144953

[29] Tumwine G, Matovu E, Kabasa JD, et al. Human brucellosis: seroprevalence and associated risk factors in agro-pastoral communities of Kiboga District, Central Uganda. BMC Public Health. 2015 Dec; 15(1): 900. PMid:26374402. https://doi .org/10.1186/s128 $89-015-2242-z$

[30] Njombe A, Msanga Y, Mbwambo N, et al. The Tanzania dairy industry: Status, opportunities and prospects. 2011 undefined. 